\title{
Diversity and Inclusion Favoritism: Creating Distributive Injustices That Erode Organizational Identity
}

\author{
LaJuan Perronoski Fuller ${ }^{1}$ \\ ${ }^{1}$ Glenn R. Jones College of Business, Trident University International, Cypress, CA, USA \\ Correspondence: LaJuan Perronoski Fuller, Ph.D., Trident University International, Cypress, CA, USA.
}

Received: December 3, 2021

Accepted: January 4, $2022 \quad$ Available online: January 5, 2022

doi:10.11114/ijsss.v10i1.5416

URL: https://doi.org/10.11114/ijsss.v10i1.5416

\begin{abstract}
Diversity and inclusion concepts remain unclear, which has generated an explosion of new viewpoints to pursue distributive justice. These variations suggest the need for a criterion to recognize partiality or prejudices in diversity and inclusion practices. This study applies the social identity approach to investigate the impact of diversity and inclusion distributive injustices on an employee's organizational identity. Research on perceived employee distributive injustice (PEDI) suggests organizations that favor a person's social categorization or identity may more likely create unfair compensations and incentive biases. This study hypothesizes that distributive injustices can recognize diversity and inclusion practices that negatively affect an employee's organizational identity. The study consists of 451 full-time US employees. A Cronbach's alpha coefficient for distributive injustice is .94 , and organizational identity is .92 . The findings confirm that leaders and HR professionals who implement diversity and inclusion practices that favor a social characteristic or identity will erode organizational identity.
\end{abstract}

Keywords: diversity, inclusion, organizational identity, distributive injustice

\section{Introduction}

Distributive justice applies fair and impartial practices to reduce disparities between diverse groups. The purpose of distributive justice is to conceptualize diversity through perceptions of "inclusion" (Larson \& Holman, 1994). The term "inclusion" is the ability to accept an employee's unique characteristic by developing their sense of belongingness to the organization (Shore et al., 2011). However, diversity and inclusion definitions remain unclear (Shore et al., 2018) and have generated an infinite number of distributive justice practices in the workplace (Rabl et al., 2020).

Organizational leaders and human resource (HR) professionals rely on distributive justice practices to create positive employee behaviors (Hur \& Ha, 2019), improve organizational commitment (Jehanzeb, 2020), and reduce group disparities (George et al., 2014). However, the social identity approach exposes that distributive injustice can suppress performance and merit by assigning unjust blame toward non-similar employee groups. Therefore, the social identity approach can recognize distributive injustices (Haslam \& Stratemeyer, 2016; Lozano \& Esrich, 2017) and clarify diversity and inclusion practices in the workplace.

The social identity approach incorporates the social identity and social norm theories. The social identity theory is consistent with the meaning of inclusion by Shore et al. (2011) and suggests that people rely on social groups to navigate their world (Tajfel \& Turner, 1979; Ashforth \& Mael, 1989). The social identity framework consists of social categorization, social identification, and social comparison. Consequently, unfavorable social comparisons between an employee's social identity or categorization create in-group (us) versus out-group (them) opposition (Ambrose et al., 2018). The social identity theory can detect diversity and inclusion practices that create opposition between in-group and out-group employees.

Organizations use social norms to help employees develop feelings of acceptance and belongingness (Hudson et al., 2019). However, the social norm theory proposes that labeling employees by similar (us) and non-similar (them) social characteristics can erode organizational identity (Lin et al., 2020). The social norm theory can rationalize the impact of diversity and inclusion practices that rely solely on an employee's social characteristics. Therefore, if employees perceive diversity and inclusion practices as unfavorable to their in-group, they will perceive those practices as a distributive injustice and negatively affect their organizational identity. Because there has been an explosion of ideas on diversity and inclusion (Rabl et al., 2020), organizational leaders need clarity to assess types of diversity and inclusion 
practices that may erode an employee's organizational identity.

Research Question 1: Do diversity and inclusion practices that rely on an employee's social categorization or identification measure as a distributive injustice?

Research Question 2: Do diversity and inclusion practices that measure as a distributive injustice have a negative relationship with an employee's organizational identity?

\section{Literature Review}

\subsection{Diversity and Inclusion}

Diversity is a process that acknowledges employee dissimilarities and recognizes value within their differences (Thomas and Ely, 1996). Diversity management practices acknowledge and recognize differences and compel action through laws, policies, and procedures. These compliance actions explain how organizations attempt to resolve tensions between social groups swiftly (Ely \& Thomas, 2001) and encourage employees to comply without the threat of mandates (Dass \& Parker, 1999). However, it is unclear if swift actions without an effective evaluation method may lead to distributive injustices toward certain social groups represented within the organization.

Morals and identity are social norm pathways (Lapinski \& Rimal, 2005; Rimal et al., 2005) that pressure leaders to reduce the consequences of an employee's social environment (Bell \& Cox, 2015; Dannals \& Miller, 2017). Organizational identity is an enforcement pathway that influences harmony between employees (Young, 2015). Social norm pathways suggest that inclusion is a suitable compliance measure to address disparities in the workplace (Dannals \& Miller, 2017). Nonetheless, social pressure on leaders to establish inclusion may overlook distributive justice without a proper evaluation method.

The social norm theory posits that misperceptions, biases, and stereotypes influence how in-groups (us) think and act toward out-groups (them). The SNT framework reveals that distributive justice encourages positive behaviors and attitudes between employees (Colquitt and Rodell, 2015). The findings concur with previous research on in-group and out-group divergent power dynamics (Tajfel \& Turner, 1979; Ambrose \& Schnitzlein, 2017; Farivar et al., 2018). However, pursuing organizational legitimacy based on societal pressure may unintentionally erode organizational identity in pursuing justice.

Organizations rely on mission statements to affirm their position on diversity and inclusion (Danowitz \& Hanappi-Egger, 2012). Leadership's ability to incorporate diversity and inclusion promotes an environment of fairness in the workplace (Podsiadlowski et al., 2013). However, the social norm theory suggests that social identities create "us" versus "them" power dynamics (Farivar et al., 2018) as employees attempt to match with non-similar attributes (Rabl et al., 2020). Because organizational leadership correlates with distributive justice (Gao \& He, 2017), decision-makers who rely on social norm pressures for swift actions may generate unfairness in the workplace (Pryor et al., 2019). This study suggests that lack of a distributive injustice scale leads to unintentional collective prejudices and negatively affects an employee's organizational identity.

The social identity theory consists of three levels that may clarify how employees respond to practices that adversely affect a social collective (Johnson et al., 2006) and influence organizational membership (Piening et al., 2020). First, the personal level describes a person's sense of uniqueness and self-image (Johnson et al., 2006), consistent with the conceptualization of inclusion. Inclusion is the degree to which a diverse person feels an organization values their unique characteristics (Shore et al., 2011). Next, the relational level evaluates an employee's self-worth by the quality of their relationship with the organization (Brewer \& Gardner, 1996). Finally, the collective level defines employees as social groups (e.g., gender, ethnicity, sexual orientation) in which they belong. Larson and Holman's (1994) research on social groups coupled with Farivar et al.'s (2018) study on in-group is consistent with diversity and inclusion literature. Therefore, applying the social identity theory may add to our understanding of employee perception of diversity and inclusion due to social affiliation. Table 1 provides definitions for each social identity theory stage.

Table 1. Social Identity Theory Employee Stages

\begin{tabular}{ll}
\hline Social Identity Employee Stage(s) & Definitions \\
\hline Social Categorization & $\begin{array}{l}\text { Diversity and inclusion practice with partiality toward an employee's social } \\
\text { categorization is a distributive injustice. }\end{array}$ \\
Social Identification & $\begin{array}{l}\text { Diversity and inclusion practice with partiality toward an employee's social } \\
\text { identification is a distributive injustice. }\end{array}$ \\
Social Comparison & $\begin{array}{l}\text { Diversity and inclusion practice with unfair compensation and meritless } \\
\text { incentives based on an employee's social categorization or identification is a } \\
\text { distributive injustice. }\end{array}$ \\
\hline
\end{tabular}


The sense of belongingness and feelings of value based on unique characteristics are attributes of inclusion (Shore et al., 2011). Organizations that rely on the integration and learning approach emphasize belongingness, value, and respect for employee differences (Podsiadlowski et al., 2013; Rabl et al., 2020). Integration and learning approaches remove barriers by enhancing fair treatment for all employees. Therefore, additional studies are needed to counteract unintentional distributive injustices in pursuit of diversity and inclusion.

Organizations are dynamic social entities that balance employees' diverse needs while pursuing organizational goals (Lin et al., 2020). Diversity is the difference, dissimilitude, or unlikeness between persons in manner, disposition, and characteristics. However, distributive injustices create biased laws, policies, and procedures that form contrariety between different characteristics. Contrariety is the opposition of characteristics, facts, or state of mind between two or more groups. It is plausible that contrariety may pervert distributive justice, which degrades an organization's legitimacy.

\subsection{Organizational Identity}

Organizational legitimacy is the proper alignment between an organization's values and a social value system (Dowling and Pfeffer, 1975). Studies in diversity widely accept that diversity management is a critical function of organizational legitimacy (Lazano \& Esrich, 2017). Hudson et al. (2019) confirmed that distributive justice predicts organizational legitimacy, a prerequisite for organizational identity (Scott \& Lane, 2000). However, organizational policies and procedures based on social, not factual norms, degrade employees' organizational legitimacy (Yuan et al., 2016; Hao et al., 2016; Guo et al., 2019). This concept suggests that distributive injustice can evaluate the efficiency of diversity management practices by the division it creates between employee groups.

Organizations use coercive conformal, normative isomorphism, and mimicry to establish legitimacy in a social value system (Tang, 2017). Coercive isomorphisms relate to the institutional pressures produced by organizational interdependence. Leaders rely on organizational strength to influence employee behavior. Normative isomorphisms are the requirements of various professional organizations within that industry. Memetive isomorphisms refer to organizational challenges. Organizations that succeed in meeting isomorphisms are used as a benchmark by their competition to avoid risks and stressors associated with social value systems. However, the institutional perspective suggests that organizational legitimacy is easy to manipulate. Therefore, social pressures may manipulate institutional perspectives on diversity and inclusion that adversely affect organizational identity.

Organizational identity is derivative of the social identity theory and explains it as a rediscovery of employee emotions in the workplace (Albert et al., 2000). Similarly, employee perceptions establish levels of distinction to their organization's identity (Lyngdoh et al., 2018). However, the social norm theory suggests that social pressure and misperceptions may lead to biases, stereotypes and adversely affects organizational membership (Olkkonen \& Lipponen, 2006). Therefore, organizational leaders that favor one social collective over another can adversely affect employee emotions and degrade organizational identity (Ambrose \& Schnitzlein, 2017).

Farivar et al. (2018) suggest that employees measure their self-perception by in-group similarity. However, organizations that favor a particular social group as less likely to care about operational efficiency (Tang, 2017). Lack of operational efficiency is consistent with findings that distributive injustice negatively affects co-workers' psychological health (An et al., 2015), influences anxiety (Lee et al., 2019), and links to organizational identity. Comparatively, distributive injustice degrades employees' psychological bonds (Berthelsen et al., 2018) and self-perception within the organization (Farivar et al., 2018). It is plausible that a proper distributive injustice measurement will recognize employees' self-perceptions and likely explain the erosion of their organizational membership (Lin et al., 2020).

\subsection{Distributive Injustice}

Distributive justice relates to an employee's perception of fair treatment. Employees who perceive practices are fair, have positive attitudes (Kivimäkiet al., 2003), and measure high in feelings of organizational legitimacy (Hudson et al., 2019). Fairness establishes legitimacy and is a prerequisite for establishing organizational identity (Ambrose \& Schnitzlein, 2017). Therefore, a proper distributive injustice scale should negatively influence organizational identity.

Furthermore, distributive injustice negatively influences employee conduct in the workplace (Marescaux et al., 2019). These findings explain the purpose of needing a method to recognize discriminatory injustices (Neuberg \& DeScioli, 2015; Haslam \& Stratemeyer, 2016). Similarly, diversity and inclusion practices require a distributive injustice evaluation to ensure justice does not become camouflaged. Therefore, misperceptions and injustices may provide a more accurate method to recognize social norm discriminatory practices.

Social norms, government regulations, and organizational practices influence employee perception and leadership decision-making (Lin et al., 2020). These three conditions confirm that organizations are likely to benchmark successful coercive conformal, normative isomorphism, and mimicry to establish organizational legitimacy (Tang, 2017). 
Comparatively, the social identity theory's personal level can describe how an employee's self-perception may link diversity and inclusion with organizational membership. Thus, proper evaluation of diversity and inclusion practices is necessary to build organizational identity.

Distributive injustice explains how employees assess fairness based on the level of division it creates (Asj'ari et al., 2020). The ability to assess fairness suggests that distributive injustice may be a reasonable evaluation method for organizational diversity and inclusion practices. Because diversity and inclusion attempt to promote employee belongingness, value, and respect, distributive injustice can recognize ineffective practices by the division they create between two or more collective social groups. According to Hao et al. (2016), employees compare themselves by favorable/unfavorable outcomes, which affects their familiarity with the organization (Guo et al., 2019). Moreover, unfavorable comparisons can establish misunderstandings among employee social groups and impacts their familiarity with the organization (Yuan et al., 2016). It is plausible that distributive justice that ignores work performance may establish injustices in the workplace.

Distributive injustices are organizational practices contrary to job performance (Fuller, 2021). As a result, this research develops a perceived employee distributive injustice (PEDI) scale using the SI approach to account for organizational practices. Fuller (2021) confirms the scale with a Cronbach's alpha coefficient at .95 and a significant negative relationship on an employee's psychological bond (organizational commitment). The research findings suggest that PEDI may help leaders and managers understand how diversity and inclusion practices based solely on an employee's social characteristics may degrade their organizational identity. Therefore, PEDI's criteria will more likely present a theoretical and practical application for leaders and HR professionals.

Furthermore, PEDI measures distributive injustices as practices that value social groups over work performance. Additionally, PEDI uses social group characteristics to validate employee perceptions of policies that create unfair workplace compensations and incentives that lack merit in job performance. Because diversity and inclusion are not well-defined (Shore et al., 2018), PEDI may provide further insight into diversity and inclusion practices that attempt to align organizational values with the social system values in which it operates. Figure 1 contains the conceptual model for this research.

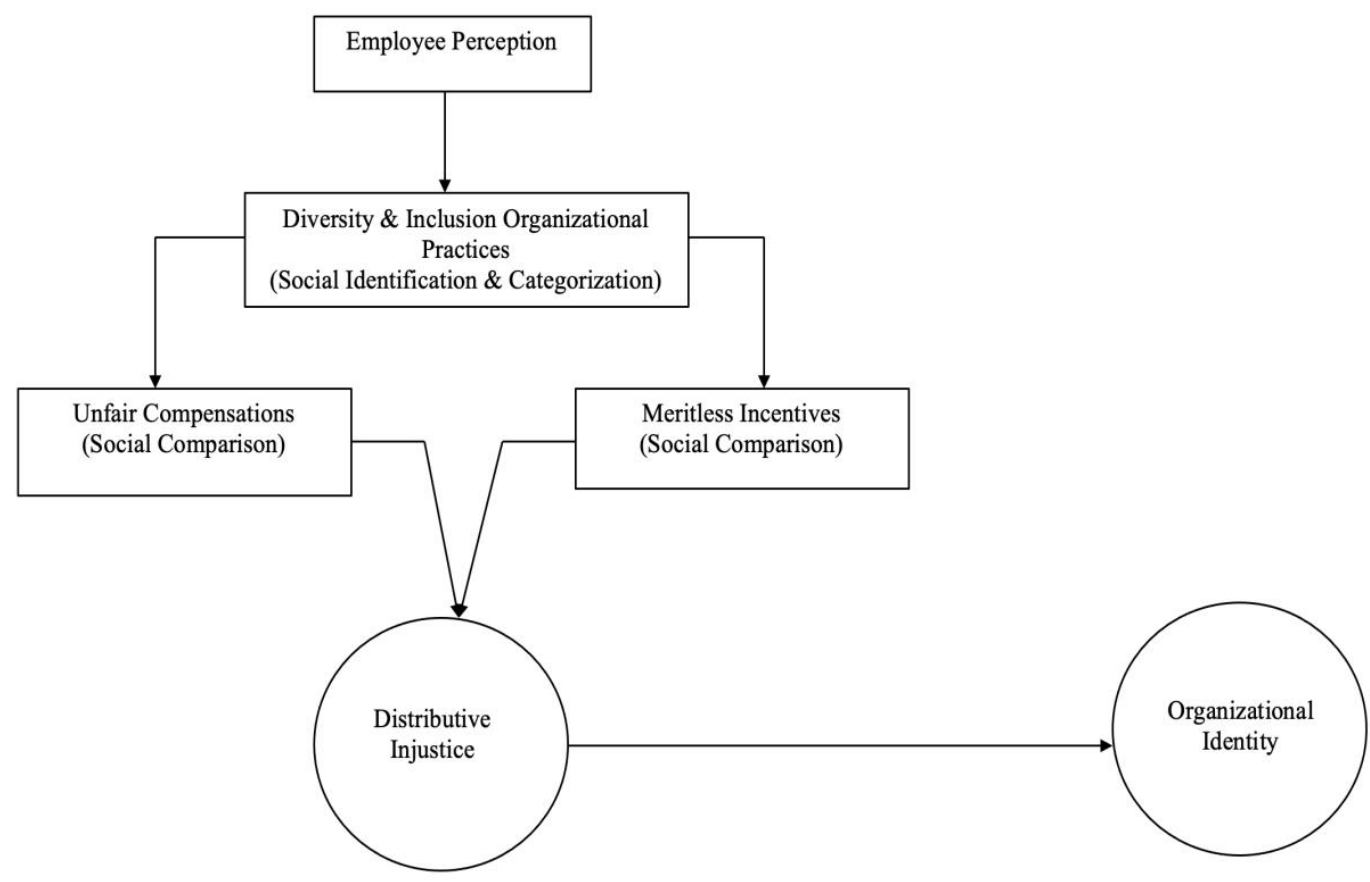

Figure 1. Distributive Injustice and Organizational Path Diagram

Therefore, this research proposes the following hypotheses.

$\mathrm{H} 1_{\mathrm{a}}$ : Employees will not perceive diversity and inclusion practices that establish unfair compensations and meritless incentives that favor a social identification or categorization as a distributive injustice.

$\mathrm{H} 1_{\mathrm{b}}$ : Employees will perceive diversity and inclusion practices that establish unfair compensations and meritless incentives that favor a social identification or categorization as a distributive injustice. 
$\mathrm{H} 2_{\mathrm{a}}$ : Diversity and inclusion practices that establish unfair compensation and meritless incentives that favor a social identification or categorization are distributive injustices and have no relationship with organizational identity.

$\mathrm{H} 2_{\mathrm{b}}$ : Diversity and inclusion practices that establish unfair compensation and meritless incentives that favor a social identification or categorization are distributive injustices and have a negative relationship with organizational identity.

\section{Method}

The investigation into distributive injustice and organizational identity uses a quantitative and cross-sectional study design. Distributive injustice consists of a 14-item scale with a previous Cronbach's alpha coefficient of .95 (Fuller, 2021). Additionally, organizational identity (OI) consists of 7-items with a previous Cronbach's alpha coefficient of .89 (Lyngdoh et al., 2018). The PEDI scale will be reverse coded to account for negative words and phrases. An additional Cronbach's alpha will confirm PEDI and OI scale reliability. Next, a Pearson correlation will measure the relationship between diversity and inclusion practices employees perceive as an injustice on their organizational identity. Then, a linear regression model will uncover the overall predictive power between the variables. Finally, an ANOVA will determine how employees' gender and age respond to race, gender, and sexual orientation diversity and inclusion practices.

The participant sample population will consist of US workforce employees. According to the US Department of Labor, current as of September 2020, the US workforce is approximately 147.79 million but does not include seasonal or part-time workers. Additionally, the study will rely on Cochran's (1988) formula to suggest an appropriate sample size with a margin of error between $4 \%-6 \%$ and a confidence interval (CI) of $95 \%$. Cochran's calculation suggests a minimum sample size of 350 participants to conduct a Pearson correlation and regression analysis. The study omits seasonal, part-time, and self-employed to reduce erroneous responses on diversity and inclusion practices on organizational identity.

The study relies on responses to the Likert-typed scale questionnaire. Fuller's (2021) PEDI scale is derivative of Colquitt and Rodell's (2015) research on perceptions of fairness and multiculturalism to investigate social attitudes. Additionally, PEDI combines racism and colorblindness scales (Henry \& Sears, 2002; Neville et al., 2000). The OI measurement consists of 7-items and is derivative of the Lyngdoh et al. (2018) study. Therefore, a pretest of these 21 total items is not necessary. Participants will answer each question using a 7-point Likert-type scale $(1=$ strongly disagree to $7=$ strongly agree). For example, it is unethical to provide rewards in the workplace by considering race/ethnicity, gender, or sexual orientation (collective social group); I find that my values and my organization's values are similar using a 7 -point Likert scale $(1=$ strongly disagree to $7=$ strongly agree $)$.

Research suggests that age and gender have an insignificant role in determining social norm influence on employee behaviors (Chizema \& Pogrebna, 2019; Jaswal, 2019). This study will apply gender and age as control variables to determine differences in distributive injustice perceptions regarding race, sexual orientation, or gender. Participants are sent surveys via SurveyMonkey ${ }^{\mathrm{TM}}$ and must select "I agree to participate." Additionally, participants who agree will sign an informed consent to access the survey questions. However, participants can stop taking the survey at any time. Participants who select "I do not agree" will not gain access to this study. Each participant understands that responses are anonymous, and no request for personally identifiable information (PII) for this study. Because Cochran's (1988) formula suggests at least 350 participants, 500 full-time employees were contacted, and 484 agreed to take this survey. Due to missing and outlier data, 33 surveys were omitted, and 451 responses were kept, which exceeds the minimum sample size of 350 .

\section{Results}

\subsection{Statistics and Analysis}

The calculations for this study summary statistics are 203 males and 248 females $(n=451)$. The most observable participant categories are females $(n=248,55 \%)$ between the ages of 45-60 $(n=156,35 \%)$. Percentages are rounded to the nearest whole number. Please see Table 2 for a breakdown of participant frequencies and percentages. 
Table 2. Study demographics

\begin{tabular}{lrr}
\hline Variable & $n$ & $\%$ \\
\hline Age & & \\
$18-29$ & 96 & 21.29 \\
$30-44$ & 108 & 23.95 \\
$45-60$ & 156 & 34.59 \\
$>60$ & 91 & 20.18 \\
Gender & & \\
Male & 203 & 45.01 \\
Female & 248 & 54.99 \\
\hline
\end{tabular}

The skewness and kurtosis are verified for each item. PEDI items present distributive injustice, and OI items depict organizational identity. Items with an acceptable $-2 / 2$ skewness about the mean and kurtosis $-3 / 33$ were kept and presented normal distribution but would omit any item to reduce outliers (Westfall \& Henning, 2013). Out of the 21-item survey, no questions were omitted and met skewness and kurtosis criteria. Please review Table 3 for skewness, kurtosis, and additional summary statistics.

Table 3. Normal Distribution Summary Statistics

\begin{tabular}{lrrrrrrrr}
\hline Variable & $M$ & $S D$ & $n$ & $\mathrm{SE}_{\mathrm{M}}$ & Min & Max & Skewness & Kurtosis \\
\hline PEDIO1 & 5.36 & 1.89 & 451 & 0.09 & 1.00 & 7.00 & -0.92 & -0.35 \\
PEDIO2 & 5.91 & 1.55 & 451 & 0.07 & 1.00 & 7.00 & -1.46 & 1.27 \\
PEDIQ3 & 5.42 & 1.79 & 451 & 0.08 & 1.00 & 7.00 & -0.89 & -0.31 \\
PEDIQ4 & 5.47 & 1.72 & 451 & 0.08 & 1.00 & 7.00 & -0.94 & -0.18 \\
PEDIQ5 & 5.39 & 1.75 & 451 & 0.08 & 1.00 & 7.00 & -0.94 & -0.19 \\
PEDIQ6 & 5.29 & 1.84 & 451 & 0.09 & 1.00 & 7.00 & -0.80 & -0.52 \\
PEDIO7 & 4.73 & 1.82 & 451 & 0.09 & 1.00 & 7.00 & -0.40 & -0.85 \\
PEDIO8 & 5.28 & 1.75 & 451 & 0.08 & 1.00 & 7.00 & -0.83 & -0.29 \\
PEDIQ9 & 4.97 & 1.75 & 451 & 0.08 & 1.00 & 7.00 & -0.58 & -0.61 \\
PEDIQ10 & 5.41 & 1.63 & 451 & 0.08 & 1.00 & 7.00 & -0.88 & -0.13 \\
PEDIQ11 & 5.50 & 1.76 & 451 & 0.08 & 1.00 & 7.00 & -1.08 & 0.10 \\
PEDIQ12 & 5.56 & 1.58 & 451 & 0.07 & 1.00 & 7.00 & -1.04 & 0.32 \\
PEDIQ13 & 5.31 & 1.74 & 451 & 0.08 & 1.00 & 7.00 & -0.82 & -0.39 \\
PEDIO14 & 5.08 & 1.66 & 451 & 0.08 & 1.00 & 7.00 & -0.56 & -0.54 \\
OIO1 & 4.86 & 1.57 & 451 & 0.07 & 1.00 & 7.00 & -0.41 & -0.39 \\
OIQ2 & 4.78 & 1.57 & 451 & 0.07 & 1.00 & 7.00 & -0.48 & -0.32 \\
OIQ3 & 5.07 & 1.51 & 451 & 0.07 & 1.00 & 7.00 & -0.60 & -0.12 \\
OIQ4 & 4.96 & 1.60 & 451 & 0.08 & 1.00 & 7.00 & -0.49 & -0.41 \\
OIQ5 & 4.07 & 1.73 & 451 & 0.08 & 1.00 & 7.00 & 0.01 & -0.90 \\
OIQ6 & 5.32 & 1.50 & 451 & 0.07 & 1.00 & 7.00 & -0.85 & 0.23 \\
OIQ7 & 4.47 & 1.66 & 451 & 0.08 & 1.00 & 7.00 & -0.23 & -0.63 \\
\hline
\end{tabular}

Note . PEDI = Perceived Employee Distributive Injustice; OI = Organizational Identity .

Because the surveys questions present normal distribution, PEDI's previous 14-item Cronbach's alpha of .95 (Fuller, 2021) and OI 7-item Cronbach's alpha of 89 (Lyngdoh et al., 2018) coefficients were validated for current reliability. This study applies George and Mallery (2018) criteria where an acceptable scale coefficient at $>.9$ excellent, $>.8$ good, $>.7$ acceptable, $>.6$ questionable, $>.5$ poor, and $\leq .5$ unacceptable. The results concluded that PEDI's Cronbach's alpha coefficient of 0.94 indicates excellent and OI of .84 as good reliability. However, the Cronbach's alpha "if deleted" option in IBM SPSS suggests removing OIQ5 to improve scale reliability to .92. Therefore, OI5 was removed, and a new Cronbach's alpha coefficient of .92, indicating excellent reliability for OI. As a result, PEDI'S 14-item and OI 7-item scale reliability are>.9 signifying excellent variable scale measurements. Therefore, PEDI's 14-item scale effectively measures diversity and inclusion practices that rely on social groups rather than job performance as a 
distributive injustice. Table 4 below contains the scale reliability scores.

Table 4. Scale Reliability for Independent and Dependent Variables

\begin{tabular}{lcccr}
\hline Scale & No. of Items & $\alpha$ & Lower Bound & Upper Bound \\
\hline Perceived Employee Distributive Injustice & 14 & 0.94 & 0.93 & 0.95 \\
Organizational Identity & 7 & 0.87 & 0.85 & 0.88 \\
Revised Organizational Identity & 6 & 0.92 & 0.91 & 0.93 \\
\hline
\end{tabular}

Note. The lower and upper bounds of Cronbach's $\alpha$ were calculated using a 95\% confidence interval.

PEDI and OI excellent scale reliability meet the requirement to conduct a Pearson correlation. First, IBM SPSS "Transform" function was used to transform PEDI 14-items into an IV and OI 7-items into a DV. A Pearson correlation compels relationships between PEDI and OI variables to be linear (Conover \& Iman, 1981) and Cohen's (1988) standard to study the overall relationship. Cohen's assumption exists if there is a different curvature among the points and the scatterplot in Figure 2 contains a regression line to interpret the curvature.

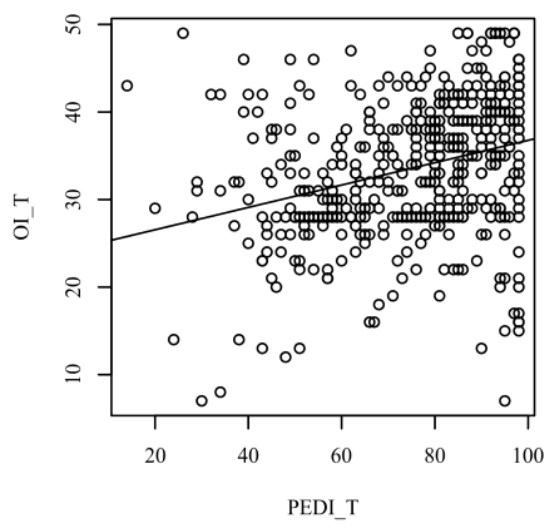

Figure 2. Correlation Scatterplot

Since the Cohen (1988) standard was applied and suggested that small effect sizes are between .10 and .29 , moderate between .30 and .49 , and large greater than .50 . Additionally, the overall correlation results are examined using an alpha value of 0.05 . The results confirm diversity and inclusion practices perceived as a distributive injustice as a significant negative relationship on an employee's identity with the organization $(\mathrm{RP}=-0.25, \mathrm{p}<.001,95 \% \mathrm{CI}[-0.34,-0.16])$. This coefficient suggests that the employee's OI decreases as distributive injustices increase. The results of the Pearson correlation are located in Table 5.

Table 5. Pearson correlation for distributive injustice and organizational identity

\begin{tabular}{lrrr}
\hline Combination & RP & $95 \%$ CI & p \\
\hline Distributive Injustice-Org Identity & -0.25 & {$[-0.34,-0.16]$} & $<.001$ \\
\hline
\end{tabular}

Note: $\mathrm{n}=451$

The study applies a Spearman correlation to validate the Pearson correlation analysis. Spearman correlation analysis corroborates the significant negative relationship between distributive injustice (PEDI) and OI at ( $r s=-0.29, \mathrm{p}<.001$, $95 \%$ CI $[-0.37,-0.20])$. The results confirm that as diversity and inclusion practices evaluated as a distributive injustice tend to increase, OI decreases. Table 6 contains the Spearman correlation corroborating results. 
Table 6. Spearman Correlation for distributive injustice and organizational identity

\begin{tabular}{lrrr}
\hline Combination & $\mathrm{r}_{\mathrm{s}}$ & $95 \% \mathrm{CI}$ & $\mathrm{p}$ \\
\hline Distributive Injustice-Org Identity & -0.29 & {$[-0.37,-0.20]$} & $<.001$ \\
\hline
\end{tabular}

Note: $\mathrm{N}=451$

There is a significant negative relationship between diversity and inclusion practices that measure as a distributive injustice and OI. Therefore, a linear regression analysis will assess the predictability of distributive injustice on OI. The comparisons are labeled as the Q-Q scatterplot (DeCarlo, 1997), but residual quantiles that deviate from the theoretical quantiles indicate unreliable estimates. The quantiles from the summary statistics did not strongly deviate from theoretical quantiles, suggesting reliable estimates, and homoscedasticity was investigated by plotting the residuals against predicted values (Bates et al., 2014; Field, 2017). The assumption is met since the points on the chart appear to be randomly distributed and have no pronounced curvature (Figure 3).

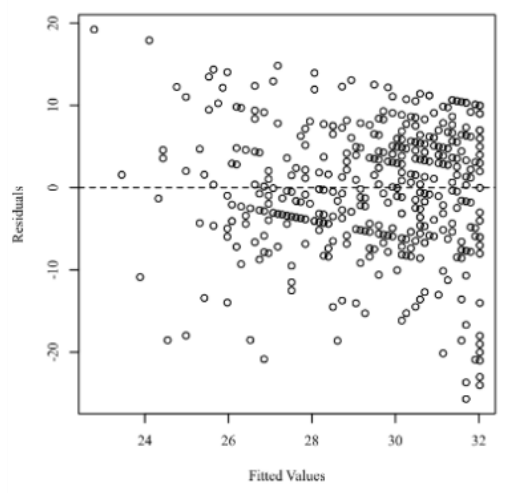

Figure 3. Homoscedasticity Residual Scatterplot

This study encompasses one predictor variable (PEDI). Therefore, multicollinearity and Variance Inflation Factors (VIF) application does not apply. However, standard practice calculates and plots studentized residuals (Field, 2017). The observation on studentized residual greater than 3.11 and t-distribution of 450 degrees of freedom was contemplated on the overall influence in the model results. Each point presents the observations and Studentized residuals greater than 3.11 in Figure 4.

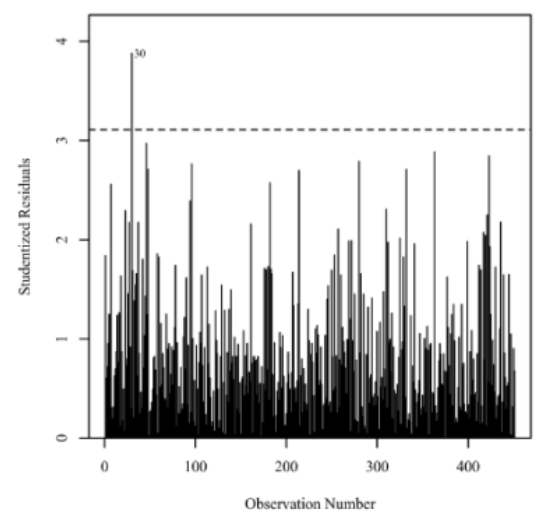

Figure 4. Studentized residuals plot for outlier detection

The overall linear regression model output results were significant at, $\mathrm{F}(1,449)=30.27, \mathrm{p}<.001, \mathrm{R} 2=0.06$, indicating distributive injustice significantly predicts OI, $\mathrm{B}=-0.11, \mathrm{t}(449)=-5.50, \mathrm{p}<.001$. Thus, on average, a one-unit increase of distributive injustice will decrease the value of OI at near .11. Table 7 contains the output for this linear regression model. 
Table 7. PEDI and OI Linear Regression Model Output

\begin{tabular}{lrrrrrr}
\hline Variable & $\mathrm{B}$ & $\mathrm{SE}$ & $95 \%$ CI & $\beta$ & $\mathrm{t}$ & $\mathrm{p}$ \\
\hline (Intercept) & 33.56 & 0.83 & $\lceil 31.93,35.191$ & 0.00 & 40.45 & $<.001$ \\
PEDI & -0.11 & 0.02 & $\lceil-0.15,-0.07]$ & -0.25 & -5.50 & $<.001$ \\
\hline
\end{tabular}

\subsection{Ancillary Analyses}

Finally, an ANOVA analysis was conducted based on the alpha value of 0.05 for differences in gender and age control variables. However, the ANOVA results are not significant, $F(4,446)=1.47, p=.209$. This suggests no significant differences based on the respondent's age and gender. The results conclude no significant differences exist, confirming previous studies comparing these control variables on social norms and employee behaviors. However, Posthoc tests are not required as $\mathrm{p}>.05$ for Age (.463) and Gender (.081).

Table 8. Control Variable Analysis of Variance (ANOVA)

\begin{tabular}{lrrrrr}
\hline Control Variable & SS & $d f$ & $F$ & p-value & $\eta_{n}^{2}$ \\
\hline Age & 162.90 & 3 & 0.86 & .463 & 0.01 \\
Gender & 193.99 & 1 & 3.06 & .081 & 0.01 \\
Residuals & 28228.91 & 446 & & & \\
\hline
\end{tabular}

Table 9 consists of Means and standard deviations.

Table 9. Control variable table for means, standard deviations, and sample size

\begin{tabular}{lrrr}
\hline Combination & M & SD & $\mathrm{n}$ \\
\hline 18-29: Male & 28.71 & 7.46 & 45 \\
30-44: Male & 26.96 & 10.19 & 50 \\
45-60: Male & 30.64 & 7.97 & 64 \\
60+ : Male & 27.86 & 6.95 & 44 \\
18-29: Female & 28.25 & 7.27 & 51 \\
30-44: Female & 32.26 & 6.76 & 58 \\
45-60: Female & 29.66 & 8.59 & 92 \\
60+: Female & 30.17 & 6.47 & 47 \\
\hline
\end{tabular}

The Cronbach's alpha coefficient of .94 suggests that diversity and inclusion practices that value the social group over job performance measure as a distributive injustice. Additionally, Pearson correlations confirm a significant negative relationship on an employee's organizational identity. Figure 2 provides the conclusion that social identity and comparison account for distributive injustices, and Table 10 confirms the hypotheses testing. 


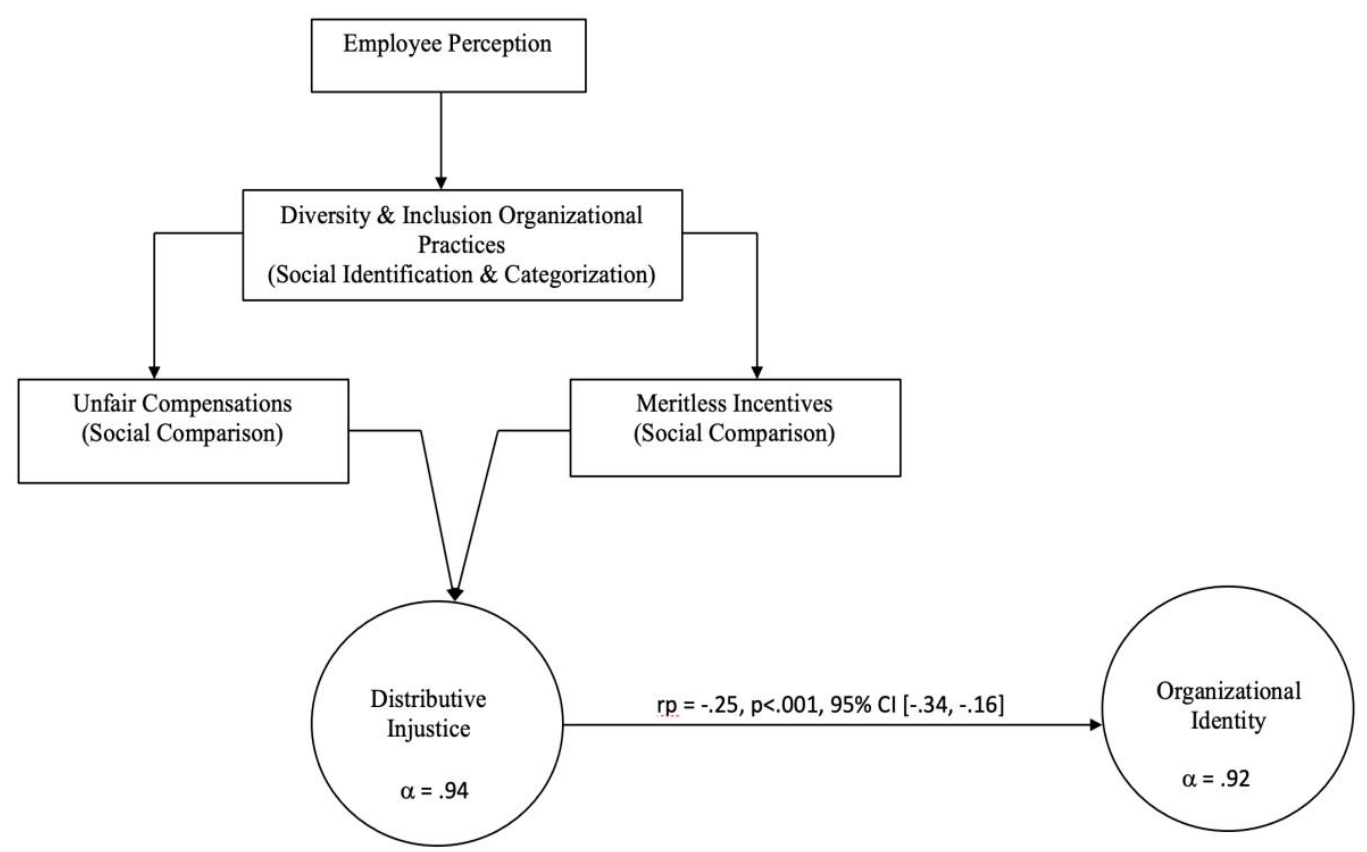

Figure 2. Distributive Injustice and Organizational Identity Model Results

\section{Discussion}

\subsection{Theoretical Implications}

This research consists of three theoretical implications. The first theoretical implication is that the social identity approach provides an acceptable method to access diversity and inclusion practices. The results of this analysis suggest that employees perceive diversity and inclusion practices that favor a particular social category or identity rather than

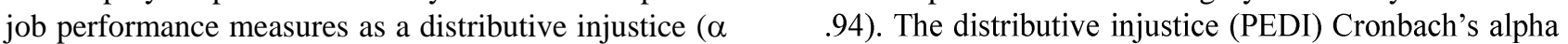
coefficient confirms that social norms correlate with categories of distributive justice (Gao \& He., 2017). However, diversity and inclusion practices that rely on social norms can create unfavorable social comparisons without a proper distributive injustice scale.

The second theoretical implication applies the social norm theory to advance diversity and inclusion literature. Pearson and Spearman correlation tests reveal that diversity and inclusion practices that favor a social identity or category erode organizational identity. These results substantiate previous findings that intergroup comparisons have a relationship with organization identification (Brown, 2020). Therefore, diversity and inclusion favoritism introduce prejudices, is perceived as a distributive injustice, and degrades organizational identity.

The third theoretical implication advances diversity and inclusion literature using the social identity theory. First, social identity theory suggests that organizational membership develops at the personal and collective stages (Piening et al., 2020). The findings of this investigation confirm employee perception (personal level) of practices that favor a particular social collective (collective level) as a distributive injustice. Additionally, the results corroborate that an employee's feeling of inclusion (Johnson et al., 2006; Shore et al., 2011) can be measured by organizational identity and adversely impacted by diversity and inclusion practices that create unfair compensations and meritless incentives.

Furthermore, the social identity theory explains that inclusion is the degree to which a diverse person feels valuable based on their unique characteristic (Shore et al., 2018). However, diversity and inclusion practices based solely on a unique social characteristic reduce feelings of "inclusion" by employees of non-unique social characteristics. This verdict reveals that the explosion of ideas on diversity and inclusion can unintentionally introduce biases, stereotypes, or prejudices toward non-similar social categories. Therefore, PEDI advances the social identity approach and provides a criterion to assess diversity and inclusion practices in the workplace.

\subsection{Practical Implications}

There are practical implications for diversity and inclusion practices. First, the result from this research verifies that diversity and inclusion establish levels of organizational identity (Ambrose \& Schnitzlein, 2017). Comparatively, 
distributive injustice measurements can recognize diversity and inclusion practices that are exclusionary. Next, subjective norms are likely built on biases and stereotypes to create compensations (Pryor et al., 2019). Leaders and HR professionals should use PEDI to assess diversity and inclusion practices that apply subjective norms in the workplace.

Distributive injustice measurements advance our practical understanding of in-group and out-group comparisons to develop an employee's feeling of self-perception (Farivar et al., 2018). The negative correlation between distributive injustice and organizational identity suggests that unfavorable in-group versus out-group comparisons degrade an employee's membership with the organization. This outcome confirms that diversity and inclusion are critical for organizational identity (Lazano \& Esrich, 2017) but requires a distributive injustice measurement to evaluate program efficiency. Therefore, distributive injustice measurements can recognize compensation and incentive favoritism to reduce the erosion of organizational identity.

The goal of organizational leaders and HR professionals is to decrease disparities between employees. However, previous findings support that in-group (us) versus out-group (them) comparisons create opposition in an organization (Ambrose \& Schnitzlein, 2017; Farivar et al., 2018). As a result, diversity and inclusion practices that favor a social categorization or identification advances knowledge in organizational identity literature. Similarly, the negative relationship explains that social comparisons continue to influence employee behavior in the workplace (Colquitt and Rodell, 2015; Rabl et al., 2020). Therefore, diversity and inclusion practices that favor a social categorization or identity contain prejudices toward non-similar employees.

Diversity and inclusion practices are effective compliance measures to assess policymaking (Dannals \& Miller, 2017). However, PEDI confirms that compliance measures should assess diversity and inclusion practices by the opposition it creates (Asj'ari et al., 2020). Therefore, diversity and inclusion practices that promote social collectives are likely to measure as a distributive injustice (Astuti \& Ingsih, 2019). These practices suggest that diversity and inclusion preferences toward a particular in-group (us) such as gender, race, sexual orientation, or sexual identity may adversely affect the organizational identity of out-group employees (them).

\subsection{Limitations}

This cross-sectional study method has some research limitations. First, correlations between employee measurements of PEDI and OI can change over time, industry, or culture. Changes in sampling suggest that the ANOVA for 451 participants might yield different results if two or more countries were used as a control variable. Additionally, future research should determine if distributive injustice or diversity management is a more salient predictor of OI. Therefore, researchers should conduct multiple linear regression or structural equation modeling to identify the most robust predictor of OI.

The entire US employee workforce was not measured for this research, and this study may have sample biases. However, the data was collected from 451 full-time US employees with a 4\%-6\% margin of error to reduce potential sample biases. Additionally, the 451 participants may have rushed to answer the survey questions. Therefore, this survey only contains 23 questions items to mitigate this concern. This study uses previously accepted distributive injustice and organizational identity measurement scales to mitigate survey biases. Additionally, PEDI uses generic terms such as gender, race, sexual orientation, and sexual identity to reduce respondent answer biases toward opposing social group characteristics.

Organization and leadership ethics can influence an employee's organizational identity (Kim \& Beerh, 2020). Therefore, further research should investigate relationships between ethical leadership and organizational identity. Advancing studies on leadership styles may fill gaps in the literature on the potential moderating or mediating effects between employee perception of distributive injustice and the erosion of organizational identity. Finally, this investigation reveals that gender and age participants do not differ about social categories such as race, sexual orientation, and sexual identity. However, more research is needed to validate the age and gender differences on diversity and inclusion distributive injustices on citizenship behavior. Therefore, this study encourages organizational leaders, and HR professionals can evaluate diversity and inclusion practices by measuring the erosion of their organization's identity.

\section{Conclusion}

Organizational leaders and HR professionals rely on distributive justice to reduce disparities (Hudson et al., 2019) and align organizational goals (Lin et al., 2020). However, due to the explosion of diversity and inclusion ideas (Rabl et al., 2020), a proper assessment is required to prevent distributive injustices in the workplace. This study applied the social identity approach to determine diversity and inclusion practices that may measure as a distributive injustice. The findings confirm that diversity and inclusion favoritism can create perceptions of injustice (Arasli \& Tumer 2008; Keles et al., 2011). Leaders and HR professionals can evaluate diversity and inclusion favoritism using this PEDI distributive injustice scale. PEDI recognizes practices that may create "us" versus "them" opposition and degrade organizational 
identity. A house or organization that is divided cannot stand. Therefore, government officials, leaders, and HR professionals can assess diversity and inclusion practices by the distributive injustices they create.

\section{References}

Albert, S., Ashforth, B., \& Dutton, J. (2000). Organizational Identity and Identification: Charting New Waters and Building New Bridges. Academy of Management Review, 25(1), 13-20. https://doi.org/10.5465/amr.2000.2791600

Ambrose, S. C., Matthews, L. M., \& Rutherford, B. N. (2018). Cross-functional teams and social identity theory: A study of sales and operations planning (S\&OP). Journal of Business Research, 92, 270-278. https://doi.org/10.1016/j.jbusres.2018.07.052

Ambrose, S. C., \& Schnitzlen, N. (2017). What Makes For the Best Rivalries in Individual Sports and How Marketers Capitalize on Them? Sports Management Quarterly, 26(4), 223-234.

An, S. J., Chung, Y. K., Kim, B. H., Kwak, K. M., Son, J. S., \& Koo, J. W. (2015). The effect of organizational system on self-rated depression in a panel of male municipal firefighters. Annals of Occupational Environmental Medicine, 27(1), 1-15. https://doi.org/10.1186/s40557-014-0044-x

Ashforth, B. E., \& Mael, F. (1989). Social identity theory and the organization. Academy of Management Review, 14, 20-39. https://doi.org/10.2307/258189

Arasli, H., \& Tumer, M. (2008). Nepotism, favoritism, and cronyism: A study of their effects on job stress and job satisfaction in the banking industry of North Cyprus. Social Behavior and Personality, 36, 1237-1250. https://doi.org/10.2224/sbp.2008.36.9.1237

Asj'ari, F., Utomo, S. P., \& Suharyanto. (2020). Procedural justice and distributive justice: Employees' organizational commitments in creative industry. Russian Journal of Agricultural and Socio-Economic Sciences, 97(1), 142-149. https://doi.org/10.18551/rjoas.2020-01.18

Astuti, S. D., \& Ingsih, K. (2019). Distributive justice improves job satisfaction and procedural justice increases organizational commitment. Calitatea, 20(169), 93-98.

Bates, D., Mächler, M., Bolker, B., \& Walker, S. (2014). Fitting linear mixed-effects models using lme4: arXiv preprint arXiv, Journal of Statistical Software. https://doi.org/10.18637/jss.v067.io1

Bell, D. C., \& Cox, M. L. (2015). Social norms: Do we love norms too much? Journal of Family Theory \& Review, 7, 28-46. https://doi.org/10.1111/jftr.12059

Berthelsen, H., Conway, P. M., \& Clausen, T. (2018). Is organizational justice climate at the workplace associated with individual-level quality of care and organizational affective commitment? A multi-level, cross-sectional study on dentistry in Sweden. International Archives of Occupational and Environmental Health, 91(2), 237-245. https://doi.org/10.1007/s00420-017-1275-2

Brewer, M. B., \& Gardner, W. (1996). Who is this "we"? Levels of collective identity and self representations. Journal of Personality and Social Psychology, 71, 83-93. https://doi.org/10.1037/0022-3514.71.1.83

Brown, R. (2020). The social identity approach: Appraising the Tajfellian legacy. British Journal of Social Psychology, 59(1), 5-25. https://doi.org/10.1111/bjso.12349

Chizema, A., \& Pogrebna, G. (2019). The impact of government integrity and culture on corporate leadership practices: Evidence from the field and the laboratory. Leadership Quarterly, 30(5), 101303. https://doi.org/10.1016/j.leaqua.2019.07.001

Cohen, J. (1988). Statistical power analysis for the behavior sciences (2nd ed.). West Publishing Company.

Colquitt, J. A., \& Rodell, J. B. (2015). Measuring justice and fairness. In R. S. Cropanzano \& M. L. Ambrose (Eds.), The Oxford handbook of justice in the workplace (pp. 187-202). Oxford University Press.

Conover, W. J., \& Iman, R. L. (1981). Rank transformations as a bridge between parametric and nonparametric statistics. The American Statistician, 35(3), 124-129. https://doi.org/10.1080/00031305.1981.10479327

Dannals, J. E., \& Miller, D. T. (2017). Social norms in organizations. In M. A. Hitt (Ed.), Oxford research encyclopedia of business and management. https://doi.org/10.1093/acrefore/9780190224851.013.139

Danowitz, M. A., \& Hanappi-Egger, E. (2012). Diversity in organizations: Concepts and practices (pp. 137-160). Basingstoke: Palgrave Macmillan. https://doi.org/10.1007/978-1-137-28487-7

Dass, P., \& Parker, B. (1999). Strategies for managing human resource diversity: From resistance to learning. Academy of Management Executive, 13(2), 68-80. https://doi.org/10.5465/ame.1999.1899550 
DeCarlo, L. T. (1997). On the meaning and use of kurtosis. Psychological Methods, 2(3), 292-307. https://doi.org/10.1037/1082-989X.2.3.292

Dowling, J., \& Pfeffer, J. (1975). Organizational Legitimacy: Social Values and Organizational Behavior. Pacific Sociological Review, 18(1), 122-136. https://doi.org/10.2307/1388226

Farivar, S., Turel, O., \& Yuan, Y. (2018). Skewing users' rational risk considerations in social commerce: An empirical examination of the role of social identification. Information \& Management, 55(8), 1038-1048. https://doi.org/10.1016/j.im.2018.05.008

Field, A. (2017). Discovering statistics using IBM SPSS statistics: North American edition. Sage Publications.

Fuller, L. (2021). Distributive Injustice: Leadership Adherence to Social Norm Pressures and the Negative Impact on Organizational Commitment. International Business Research, 14(9), 21-37. https://doi.org/10.5539/ibr.v14n9p21

Gao, Y., \& He, W. (2017). Corporate social responsibility and employee organizational citizenship behavior: The pivotal roles of ethical leadership and organizational justice. Management Decision, 55(2), 294-309. https://doi.org/10.1108/MD-05-2016-0284

George, I. N., Ukpong, D. E., \& Imah, E. E. (2014). Cultural diversity of marriage sustainability in Nigeria: Strengths and challenges. Sociology and Anthropology, 2(1), 7-14. https://doi.org/10.13189/sa.2014.020102

George, D., \& Mallery, P. (2018). IBM SPSS Statistics 25 Step by Step. https://doi.org/10.4324/9781351033909

Guo, X., Heinberg, M., \& Zou, S. (2019). Enhancing consumer attitude toward culturally mixed symbolic products from foreign global brands in an emerging-market setting: The role of cultural respect. Journal of International Marketing, 27(3), 79-97. https://doi.org/10.1177/1069031X19843912

Hao, J., Li, D., Peng, L., Peng, S., \& Torelli, C. J. (2016). Advancing our understanding of culture mixing. Journal of Cross-Cultural Psychology, 47(10), 1257-1267. https://doi.org/10.1177/0022022116670514

Haslam, N., \& Stratemeyer, M. (2016). Recent research on dehumanization. Current Opinion in Psychology, 11, 25-29. https://doi.org/10.1016/j.copsyc.2016.03.009

Henry, P., \& Sears, D. (2002). The Symbolic Racism 2000 Scale. Political Psychology, 23, 253-283. https://doi.org/10.1111/0162-895X.00281

Hudson, S., González-Gómez, H. V., \& Claasen, C. (2019). Legitimacy, particularism and employee commitment and justice. Journal of Business Ethics, 157(3), 589-603. https://doi.org/10.1007/s10551-017-3685-1

Hur, H., \& Ha, H. (2019). The link between perceptions of fairness, job training opportunity and at-will employees' work attitudes: Lessons from US. Georgia state government. European Journal of Training and Development, 43, 375-397. https://doi.org/10.1108/EJTD-09-2018-0090

Jaswal, P. (2019). Relationship between organizational citizenship behavior and organizational commitment. Research Review International Journal of Multidisciplinary, 4(5), 7. https://doi.org/10.9756/SIJASREE/V7I2/03050170201

Jehanzeb, K. (2020). Does perceived organizational support and employee development influence organizational citizenship behavior? Person-organization fit as moderator. European Journal of Training and Development, 44(6/7), 637-657. https://doi.org/10.1108/EJTD-02-2020-0032

Johnson, R. E., Selenta, C., \& Lord, R. G. (2006). When organizational justice and the self-concept meet: Consequences for the organization and its members. Organizational Behavior and Human Decision Processes, 99, 175-201. https://doi.org/10.1016/j.obhdp.2005.07.005

Keles, H. N., Ozkan, T. K., \& Bezirci, M. (2011). A study on the effects of nepotism, favoritism and cronyism on organizational trust in the auditing process in family businesses in Turkey. International Business \& Economics Research Journal, 10(9), 9-16. https://doi.org/10.19030/iber.v10i9.5622

Kim, M., \& Beehr, T. A. (2020). Empowering leadership: Leading people to be present through affective organizational commitment? International Journal of Human Resource Management, 31(16), 2017-2044. https://doi.org/10.1080/09585192.2018.1424017

Kivimäki, M., Elovainio, M., Vahtera, J., Virtanen, M., \& Stansfeld, S. A. (2003). Association between organizational inequity and incidence of psychiatric disorders in female employees. Psychology and Medicine, 33(2), 319-326. https://doi.org/10.1017/S0033291702006591

Lapinski, M. K., \& Rimal, R. N. (2005). An explication of social norms. Communication theory, 15(2), 127-147. https://doi.org/10.1111/j.1468-2885.2005.tb00329.x 
Larson, J. H., \& Holman, T. B. (1994). Premarital predictors of marital quality and stability. Family Relations, 228-237. https://doi.org/10.2307/585327

Lee, H., Um, K., Ju, Y., Lee, S., Choi, M., Paek, D., \& Cho, S. (2019). Association between organizational justice and depressive symptoms among securities company workers. Annals of Occupational and Environmental Medicine, 31(1), e7-e7. https://doi.org/10.35371/aoem.2019.31.e7

Lin, X., Lu, F., \& Liang, X. (2020). Legitimized identity vs identifiable legitimacy: Toward a theoretical framework of the relationship between organizational identity and organizational legitimacy. Nankai Business Review International, 11(1), 102-120. https://doi.org/10.1108/NBRI-03-2019-0009

Lozano, J. F., \& Escrich, T. (2017). Cultural diversity in business: A critical reflection on the ideology of tolerance. Journal of Business Ethics, 142(4), 679-696. https://doi.org/10.1007/s10551-016-3113-y

Lyngdoh, T., Liu, A. H., \& Sridhar, G. (2018). Applying positive psychology to selling behaviors: A moderatedmediation analysis integrating subjective well-being, coping and organizational identity. Journal of Business Research, 92, 142-153. https://doi.org/10.1016/j.jbusres.2018.07.020

Marescaux, E., De Winne, S., \& Sels, L. (2019). Idiosyncratic deals from a distributive justice perspective: Examining co-workers' voice behavior. Journal of Business Ethics, 154(1), 263-281. https://doi.org/10.1007/s10551-016-3400-7

Neuberg, S. L., \& DeScioli, P. (2015). Prejudices: Managing perceived threats to group life. In D. M. Buss (Ed.), The handbook of evolutionary psychology (pp. 669-683). Wiley. https://doi.org/10.1002/9781119125563.evpsych228

Neville, H. A., Lilly, R. L., Duran, G., Lee, R. M., \& Browne, L. (2000). Construction and initial validation of the Color-Blind Racial Attitudes Scale (CoBRAS). Journal of Counseling Psychology, 47, 59-70. https://doi.org/10.1037/0022-0167.47.1.59

Olkkonen, M., \& Lipponen, J. (2006) Relationships between organizational justice, identification with organization and work unit, and group-related outcomes. Organizational Behavior and Human Decision Processes, 100(2), 202-215. ISSN 0749-5978, https://doi.org/10.1016/j.obhdp.2005.08.007

Piening, E. P., Salge, T. O., Antons, D., \& Kreiner, G. E. (2020). Standing together or falling apart? understanding employees' responses to organizational identity threats. The Academy of Management Review, 45(2), 325-351. https://doi.org/10.5465/amr.2016.0457

Podsiadlowski, A., Gröschke, D., Kogler, M., Springer, C., \& vander Zee, K. I. (2013). Managing a culturally diverse workforce: diversity perspectives in organizations. International Journal of Intercultural Relations, 37(2), 159-175. https://doi.org/10.1016/j.ijintrel.2012.09.001

Pryor, C., Perfors, A., \& Howe, P. D. L. (2019). Even arbitrary norms influence moral decision making. Nature of Human Behavior, 3, 57-62. https://doi.org/10.1038/s41562-018-0489-y

Rabl, T., Carmen Triana, M., Byun, S., \& Bosch, L. (2020). Diversity Management Efforts as an Ethical Responsibility: How Employees' Perceptions of an Organizational Integration and Learning Approach to Diversity Affect Employee Behavior. Journal of Business Ethics, 161, 531-550. https://doi.org/10.1007/s10551-018-3849-7

Rimal, R. N., Lapinski, M. K., Cook, R. J., \& Real, K. (2005). Moving toward a theory of normative influences: How perceived benefits and similarity moderate the impact of descriptive norms on behaviors. Journal of health communication, 10(5), 433-450. https://doi.org/10.1080/10810730591009880

Rupp, D. E., \& Spencer, S. (2006). When customers lash out: The effects of customer interactional injustice on emotional labor and the mediating role of discrete emotions. Journal of Applied Psychology, 91(4), 971-978. https://doi.org/10.1037/0021-9010.91.4.971

Scott, S., \& Lane, V. (2000). Fluid, Fractured, and Distinctive? In Search of a Definition of Organizational Identity. Academy of Management Review, 25(1). https://doi.org/10.5465/amr.2000.27711619

Shore, L., Randel, A., Chung, B., Dean, M., Holcombe-Ehrhart, K., \& Singh, G. (2011). Inclusion and Diversity Work Groups: A Review and Model for Future Research. Journal of Management, 37(4), 1262-1289. https://doi.org/10.1177/0149206310385943

Shore, L., Cleveland, J., \& Sanchez, D. (2018). Inclusive workplaces: A review and model. Human Resource Management Review, 28(2), 176-189. ISSN 1053-4822, https://doi.org/10.1016/j.hrmr.2017.07.003

Tajfel, H., \& Turner, J. C. (1979). An integrative theory of inter-group conflict. In W. G. Austin \& S. Worchel (Eds.), The social psychology of inter-group relations (pp. 33-47). Brooks/Cole. 
Tang, Y. Y. (2017) A Summary of Studies on Organizational Legitimacy. Open Journal of Business and Management, 5, 487-500. https://doi.org/10.4236/ojbm.2017.53042

Thomas, D. A., \& Ely, R. J. (1996). Making differences matter: A new paradigm for managing diversity. Harvard Business Review, 74(5), 79-90.

Westfall, P. H., \& Henning, K. S. S. (2013). Texts in statistical science: Understanding advanced statistical methods. Taylor \& Francis. https://doi.org/10.1201/b14398

Yuan, D., Cui, G., \& Lai, L. (2016). Sorry seems to be the hardest word: Consumer reactions to self-attributions by firms apologizing for a brand crisis. Journal of Consumer Marketing, 33(4), 281-291. https://doi.org/10.1108/JCM-02-2015-1306

Young, P. (2015). The evolution of social norms. Annual Review of Economics, 7, 359-387. https://doi.org/10.1146/annurev-economics-080614-115322

\section{Copyrights}

Copyright for this article is retained by the author(s), with first publication rights granted to the journal.

This is an open-access article distributed under the terms and conditions of the Creative Commons Attribution license which permits unrestricted use, distribution, and reproduction in any medium, provided the original work is properly cited. 